\title{
Words count: 8413 \\ The influence of institutional pressures on climate mitigation and adaptation strategies
}

\author{
Tiberio Daddi ${ }^{*}$, Raimund Bleischwitz ${ }^{2}$, Niccolò Maria Todaro ${ }^{1}$, Natalia Marzia Gusmerotti ${ }^{1}$, Maria \\ Rosa De Giacomo ${ }^{2}$
}

${ }^{1}$ Sant'Anna School of Advanced Studies, Institute of Management, Piazza Martiri della Libertà 33, 56127 Pisa, Italy.

${ }^{2}$ University College London, Institute for Sustainable Resources, Central House, 14 Upper Woburn Place, London WCIH ONN, United Kingdom.

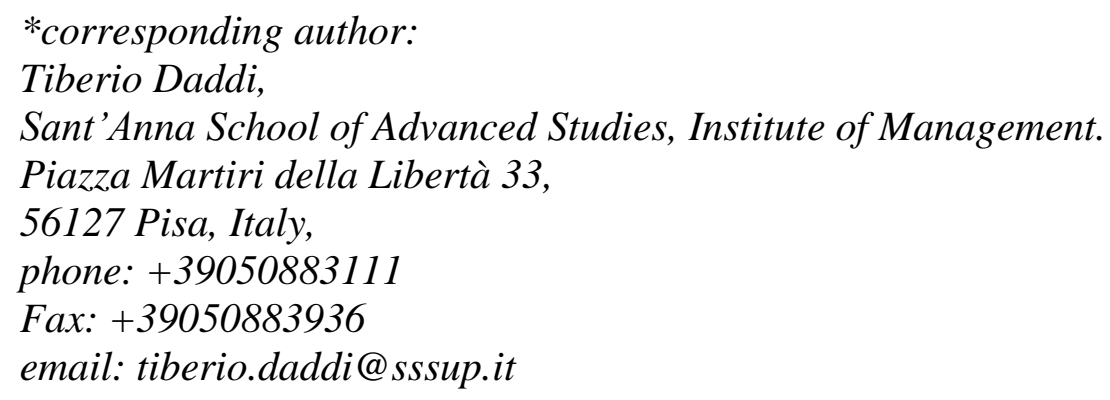

\section{Abstract}

Starting from institutional theory, this study aims to explore the effects of coercive, normative and mimetic pressures on businesses climate change mitigation and adaptation strategies. In order to test these hypotheses, the study relies on an econometric model by using data from 487 Italian manufacturing companies collected by a questionnaire-based survey. The empirical model based on a multivariate regression reveals that companies which perceive normative and mimetic pressures are more likely to have a higher climate change sensitivity. Moreover, companies with a higher climate change sensitivity are more likely to adopt both mitigation and adaptation strategies. The article provides several contributions. First the study contributes to the debate among institutional scholars by clarifying which institutional pressures exert a more incisive effect on pushing companies to adopt climate actions. Second, it highlights how internal factors play a mediating role between institutional pressures and business climate responses.

Keywords: isomorphic pressures, institutional pressures, climate change sensitivity, survey.

\section{Introduction}

The issue of firms' climate change strategies has become a topic of much debate in the academic literature. Climate change was first addressed in academic literature by environmental science and meteorology scholars in the 1970s (Freudenburg and Muselli, 2010). The policy debate is dominated by the discussions on the recent Paris agreement and decisions by the United States. The "Paris Climate Agreement" resides within the United Nations Framework Convention on Climate Change 
(UNFCCC), which addresses greenhouse gas emission mitigation, adaptation and finance starting in the year 2020. The agreement aims at responding to the threat of global climate change by keeping the rise in global temperatures to well below two degrees Celsius above pre-industrial levels this century, and to pursue efforts to limit the temperature increase even further to 1.5 degrees Celsius. The Agreement has been signed by 195 UNFCCC members, implying major implications for business. A key implication is the scale of activities: while political commitments address national plans mainly, most businesses manage operations with suppliers and customers from all over the globe. Understanding the challenges of coping with manifold pressure factors on business from a management perspective is the main purpose of this paper.

Compared with science and policy, the discussion of climate change issues in business and management studies is more recent. Only in the last decade, research has mostly focused on identifying antecedents of companies' adoption of mitigation and adaptation strategies. Despite recent interest in the topic, Goodall (2008) observed that leading management journals, like Academy of Management Journal and Academy of Management Review, completely overlooked this research topic in the years before 2006. Similarly, only nine studies were published in other leading business and management journals. The author also criticized the scope of these papers as they took a more practical rather than a theoretical approach. She justified her critical appraisal by stating that "climate change is a practical problem not a conceptual one" and "there is a time lag between the discovery of scientific knowledge and its interpretation in the social sciences".

Wittneben et al. (2012) also arrived at similar conclusions. The authors reviewed the literature on the impact of climate change on companies' behaviours and observed that "most studies have focused on identifying corporate responses to climate change and the drivers of corporate climate strategies with little attention being paid to theoretical development of models for understanding action and inaction". Similarly, Winn et al. (2011) invited scholars to adopt a more conceptual approach in the investigation of the relation between climate change and organizational responses. They suggested that research should be conducted at the "supra-organizational level of analysis" i.e., by adopting an approach based on institutional theory. Accordingly, the present study addresses previous scholars' calls for theory-based and institutional approaches to the study of antecedents of companies' climate change strategies.

More recently, Daddi et al. (2018) conducted a literature review to identify organizational and management theories utilised in studies focusing on climate change. Investigating the ISI Web of Science and Scopus bibliographic databases, the authors identified 10 management theories that have been used in at least 5 published papers. Although this literature review highlighted that institutional theory is one of the most frequently used theoretical framework to interpret businesses climate change behaviour, it also revealed several unexplored questions in the field of institutional theory. For instance, contributes on the relation between institutional pressures climate responses are still few and the study of this relation focusing on adaptation strategies can be considered a literature gap. Accordingly, the aim of the present study is to bridge this gap addressing it between theory-driven knowledge and data-driven evidence in the strategic choices made by businesses on mitigation and adaptation. In particular, as detailed in the next sections, the model aims at assessing the influence of institutional pressures on managers" "climate change sensitivity" and then, indirectly, on the adoption of mitigation and adaptation strategies.

The article proceeds as follows. The next section introduces the topic of businesses' climate change strategies and the theoretical framework in order to outline research questions and hypotheses. The following section describes the empirical research method and the variables included in the research models. The study grounds on a novel quantitative method based on data collected through an online survey. This approach follows the literature review of Daddi et al. (2018), which shows that most quantitative studies are based on data obtained by the Carbon Disclosure Project (CDP), while the 
use of original survey data is rare. The study draws on a large sample of Italian companies and, to the best of our knowledge, no studies have investigated businesses' climate change strategies, through the lens of institutional theory, in this geographical context. Then, results are presented and discussed. Finally, the last section highlights the novel contributions of the research, discusses managerial and policy implications, and draws final conclusions.

\section{Theoretical framework and hypotheses}

\subsection{Businesses' mitigation and adaptation strategies}

Several studies have shown how different factors can influence business choices with regard to climate change strategies (Stoddart et al., 2012; Backman et al., 2017). Regulatory policies, market dynamics, product and process innovation and climate-induced physical change contribute shaping companies' strategies, by creating risks and opportunities (Gasbarro et al., 2017). These factors prompt companies to adopt two key responses to climate change: mitigation and adaptation behaviours (Pinkse and Kolk, 2012). Mitigation actions aim at reducing greenhouse gas (GHG) emissions from productive activities to prevent further climatic change. Accordingly, they can be defined as "any adjustment that takes place in natural or human systems in response to actual or expected impacts of climate change, aimed at moderating harm or exploiting beneficial opportunities" (Klein et al., 2005, p. 580). Corporate responses to climate change have mostly focused on mitigation initiatives, as most efforts have been directed towards reducing greenhouse gases, especially carbon dioxide. On the other hand, business adaptation strategies have only recently been implemented as companies are increasingly acknowledging the need to build up adaptive capacity in order to effectively face extreme weather events and other impacts of climate change (Linnenluecke et al., 2012).

From the perspective of the Paris Agreement, which aims at establishing 'Nationally Determined Contributions', businesses pursue both mitigation and adaptation strategies at an international level. Although mitigation is already a central topic in policy makers' agenda, adaptation initiatives still needs to increase, and in recent years, the diffusion of this kind of measures has been led by the private sector (Nozawa et al., 2018; Lungarska and Chakir, 2018). Accordingly, the Paris Agreement on Climate Change recognizes the importance and the need to support both adaptation and mitigation strategies, while the Kyoto Protocol in 1997 mainly focused on mitigation (Gasbarro et al., 2017; UNFCCC, 2015).

As far as concern mitigation strategies, several authors have studied the management choices of companies. For example, Weinhofer and Hoffmann (2010) focused their study on identifying different approaches to climate change mitigation, such as GHG compensation, GHG reduction and carbon independence. Through a content analysis of the CDP data of 91 electricity producers, they observed that a group of companies pursued all three strategies in parallel, while another group pursued only one of the three strategic objectives. Similarly, Damert and Baumgartner (2018) focused on the automotive industry and analysed the mitigation strategies of a sample of 116 automotive firms, classifying climate change strategies in terms of governance, innovation, compensation and legitimation. The results showed that nationality (or the country of main operations) and position in the supply chain influence companies' climate change strategies.

Drivers and benefits of adaptations strategies have also been addressed. Gasbarro and Pinkse (2016) investigated the effects of climate induced physical changes on corporate responses to climate change in the oil and gas industry. They observed four main types of adaptation behaviours (pre-emptive, reactive, continuous and deferred) that are linked to different degrees of awareness and vulnerability. The link between vulnerability, awareness of climate change and adoption of adaptation strategies 
has also been studied (Pinkse and Gasbarro, 2016; Kolk et al., 2010), especially in the agricultural industry (Fleming et al., 2015; Dubey et al., 2016; Arunrat et al., 2017). For example, Sacchelli et al. (2017) investigated the role of business strategies in the response to climate change in the Italian wine industry. The authors highlighted different adaptation strategies used to ensure companies' financial solidity and economic revenues, such as insurance or fixed irrigation plants. Similarly, Masud et al. (2017) explored climate change adaptation strategies of Malaysian farmers. They identified several barriers that limit the adoption of adaptation actions such as education level, farm income, lack of credit facilities and limited access to agricultural markets.

\subsection{Institutional theory and climate change studies}

As previously stated, several scholars have observed a lack of application of organizational theories in climate change studies, and have recommended future research to deepen the theoretical elaboration of the drivers of corporate responses to climate change (Goodall, 2008). Daddi et al. (2018) addressed this by analysing the use of organizational and management theories in climate change studies. By means of a systematic literature review, the authors identified institutional theory as one of the most promising organizational theoretical framework for investigating businesses' climate change strategies.

Accordingly, this study adopts institutional theory to investigate internal drivers of corporate responses to climate change in terms of mitigation and adaptation. The importance of institutional theory is also confirmed in other fields of sustainability management (Bleischwitz 2003; Bleischwitz, 2004; Daddi et al., 2016).

Institutional theory emerged in the early 1980s. According to DiMaggio and Powell (1983), the key objective of the theory is to explain why organisations in a field tend to look and act similarly. The authors observed that, even if in the first years of the organizational life cycle all organisations have specific features, a homogeneity of organizational structures and practices can be observed even among more mature companies. Consequently, institutional theorists have identified diverse "institutional pressures" that, by delimiting and shaping organizational action, force organisations to resemble each other, thus causing "institutional isomorphism" (Scott, 1995). According to the theory, institutions exert three types of isomorphic pressures on organisations: coercive, normative and mimetic (DiMaggio and Powell, 1983). Coercive isomorphism is defined as the pressures from entities that have resources on which an organisation depends. Normative isomorphism refers to professional standards and practices established by education and training methods, professional networks and movements of employees among firms (DiMaggio, 1988; Garud et al., 2007). Mimetic isomorphism refers to imitating successful organisations when an organisation is uncertain about which strategy to pursue. Organisations are subject to these pressures because of the need to obtain legitimacy in the eyes of external constituents (e.g. clients, trade associations, regulatory actors etc.) in order to profitably pursue their business objectives.

Institutional theory has been applied in quantitative studies (e.g., Kolk et al., 2008; Amran et al., 2016), qualitative studies (e.g., Ansari et al., 2013) and conceptual studies (e.g., Doh and Guay, 2006). For instance, Galbreath (2010) used a sample of 98 firms in 3 different industries located in 10 countries to investigate the influence of institutional pressures on climate change strategies. The author assumed coercive pressures were more effective to influence firms' strategies. In their quantitative study, Delmas and Montes-Sancho (2010) investigated how different institutional pressures determine early or late participation in climate change programmes. The authors classified different businesses' behaviours toward climate change actions as non-cooperation, symbolic cooperation and substantive cooperation. Orsato et al. 2015 focused on the Brazilian financial sector using a case study analysis approach. They considered the climate change strategies as proactive 
sustainable behaviours, as in most cases they are the companies' voluntary actions. In terms of the participation of firms in voluntary climate initiatives, the study shows a higher effect of normative and mimetic pressures rather than coercive pressures. Similarly, Shinkle and Spencer (2012) focused disclosures are "shaped" by institutional pressures, which has been confirmed by other authors (Hahn et al., 2015).

These studies consider institutional pressures as directly connected with companies' climate change actions and strategies. However, according to Hoffman (2001), the choice of responses to climate change that organizations implement is much a "reflection of institutional pressures that emerge from outside the organization as it is the form of organizational structure and culture that exist inside the organization", including managerial factors. In line with this logic, the present study aims at revealing the influence of different isomorphic pressures on businesses strategies, taking into consideration the effect of such pressures on managerial factors. In particular, the theoretical model suggest that the effects of institutional pressures primarily affect "climate change sensitivity" and they indirectly stimulate the adoption of climate change strategies. Thus, external pressures contribute stimulating companies' proactivity to act on climate change, by reinforcing their perceived vulnerability and exposure to risk of climate change.

In the literature, the term sensitivity is associated with different definitions. For example, environmental sensitivity is defined as "the susceptibility of natural resources to human-induced changes such as land-use modifications that may cause their degradation" (Del Campo, 2017). As explained in the section 3, the present study associates the term to the psychological status of the companies' managers to indicate a higher level of preparedness or keenness to act on climate change compared to "simple" climate change awareness. To this matter, we observed that most studies analysed the effects of institutional pressures focusing on firms as the unit of analysis. In another words, institutional theory is commonly used to explain the adoption of specific practices by companies without focusing on individuals as the unit of analysis (Daddi et al., 2016).

The present model aims at contributing to the theoretical literature advancing that the influence of isomorphic pressures act primarily at the individual level (i.e. climate change managerial sensitivity) and, indirectly, on firms' strategies. Specifically, we aim at contributing to the literature investigating the role of climate change managerial sensitivity as a "mediator" between institutional pressures and climate change strategies. In our case, the mediator variable is defined according to Baron and Kenny (1986) as a "generative mechanism thorough which the focal independent variable is able to influence the dependent variable of interest" (pp 1173). In addition, the variable is nominated "climate change managerial sensitivity" instead of "climate change sensitivity" in order to avoid confusion with the concept of vulnerability (i.e. Vulnerability $=$ sensitivity $*$ exposure $*$ adaptive capacity).

Not all institutional pressures have a positive effect on a firms' sensitivity to climate change issues. As posited by several scholars, corporate responses to climate change are proactive and voluntary behaviours. Although institutional factors can encourage the adoption of voluntary environmental practices by managers (Delmas and Toffel, 2008), such proactive behaviours and the firms' sensitivity to climate change are difficult to induce through coercive pressures. Indeed, as stated by Porter and Van der Linde (1995), well-designed environmental regulations should allow sufficient flexibility and create incentives to stimulate innovation and organizational improvement, rather than coercively imposing performance standards. Thus:

Hypothesis 1: coercive pressures are negatively related to climate change managerial sensitivity. 
However, according to the theoretical model, normative and mimetic pressures contribute increasing

Hypothesis 2: normative pressures are positively related to climate change managerial sensitivity

Hypothesis 3: mimetic pressures are positively related to climate change managerial sensitivity climate change managerial sensitivity:

The model posits that the variable "climate change managerial sensitiveness" act as a mediator and "represents properties of the person that transform the predictor or input variable in some way" (Baron and Kenny, 1986, pp 1178). After analysing the effect on climate change managerial sensitivity, the ultimate aim of the study is to reveal the influence of these types of pressure on corporate climate change strategies. In addition, the study further contributes to extant literature by testing the influence of institutional pressures on climate change strategies, distinguishing between mitigation and adaptation strategies. Thus, the following hypothesis:

Hypothesis 4: companies with higher climate change managerial sensitivity adopt more ambitious climate mitigation strategies

Hypothesis 5: companies with higher climate change managerial sensitivity adopt more ambitious climate adaptation strategies

\section{Methods}

\subsection{Sample and data description}

The data were collected between July and September 2016, by mean of a questionnaire survey developed in collaboration with the Italian Ministry of Environment. The survey consisted of 19 multiple-choice questions and 1 open question. The questionnaire was designed by taking into account the potential problems of common method variance that can affect behavioural research. Several procedural remedies were adopted to reduce bias, such as avoiding vague concepts, complicated syntax and unfamiliar terms to minimize item ambiguity; keeping questions simple, specific, and concise; avoiding the use of bipolar numerical scale values and providing verbal labels for the midpoints of scales; and guaranteeing respondent anonymity (Podsakoff et al., 2003). Furthermore, we used Harman's single-factor test to evaluate any bias, and no single factor was found to account for most of the covariance among the measures.

The survey was provided online to a sample of 2,950 companies operating in the Italian manufacturing industries extracted from the Italian Chamber of Commerce database. These companies, mainly large and medium, represent more than $80 \%$ of the value of Italian production. An introductory letter was included, requesting recipients to forward the survey to a management member responsible for strategy planning or climate change responses. As of October 2016, 620 responses were collected, representing a $21 \%$ response rate, and 487 completed surveys were returned.

In terms of firm size, $50 \%$ of the companies in the final sample have 50 to 250 employees, and $44 \%$ have over 250. Small firms (i.e., less than 50 employees) and micro-firms (i.e., less than 10 employees) represent $6 \%$ of the final sample. In terms of turnover, $53 \%$ of the firms in the sample report annual revenues of more than $€ 50$ million, $41 \%$ report earnings between $€ 10$ million and $€ 50$ 
million and $6 \%$ report annual revenues of less than $€ 10$ million. The final sample encompasses diverse manufacturing sectors ranging from food manufacturing to pharmaceutical and metallurgical sectors. Specifically, $23 \%$ of the respondents operate in the machine industry, $15 \%$ in the metallurgical and steelmaking industry, $11 \%$ in the electronics industry and $10 \%$ in plastics and non-metals industries (see Figure 1 for the breakdown by sector).

Sector

$\%$ of respondents
Sector

$\%$ of respondents

\begin{tabular}{|c|c|c|c|}
\hline Food \& Manufacturing & $8 \%$ & Eletronics & $11 \%$ \\
\hline Textile \& Clothing & $6 \%$ & Machine industry & $23 \%$ \\
\hline Paper & $4 \%$ & Construction & $6 \%$ \\
\hline Chemical \& Petroleum & $6 \%$ & Energy & $1 \%$ \\
\hline Pharmaceutical & $4 \%$ & Furniture & $2 \%$ \\
\hline Plastic \& Non-metal & $10 \%$ & Other manufacturing & $4 \%$ \\
\hline Metallurgy & $15 \%$ & & \\
\hline
\end{tabular}

Table 1 Breakdown of respondents by sector

Most respondents hold managerial positions in environmental or safety management areas, such as Health, Safety and Environment (HSE) managers. Other respondents cover a range of functions such as CEOs, energy management, risk management and operations managers. More than $40 \%$ of the respondents have more than 16 years' working experience in their current company, while $37 \%$ report 6 to 15 years' experience in their current position. These data suggest that the surveyed respondents are well informed about their companies' decision-making and strategy planning processes on environmental issues.

\subsection{Model specifications and variables development}

As described in Figure 1, the model includes several dependent and independent variables. According to the developed hypotheses, climate change managerial sensitivity is considered a dependent variable in $\mathrm{H} 1, \mathrm{H} 2$ and $\mathrm{H} 3$, while it is an independent variable for $\mathrm{H} 4$ and $\mathrm{H} 5$. The model is based on three equations. Equation (1) investigates the influence of the three kinds of institutional pressures on the dependent variable of climate change managerial sensitivity. Equations (2) and (3) allow investigating $\mathrm{H} 4$ and $\mathrm{H} 5$, which address the relation between climate change sensitivity and mitigation and adaptation strategies, respectively. Thus, the model assumes the following equations:

$\left\{\right.$ CLIMCHMSENS $=\beta_{0}+\beta_{1}$ COERCPRESS $+\beta_{2}$ NORMPRESS $+\beta_{3}$ MIMETPRESS $+\beta_{4}$ CONTROL $+\pi_{1}$

$\left\{\right.$ MITIGSTRAT $=\varphi_{0}+\varphi_{1}$ CLIMCHMSENS $+\varphi_{2}$ CONTROL $+\pi_{1}$

$\left\{\right.$ ADAPTSTRAT $=\lambda_{0}+\lambda_{1}$ CLIMCHMSENS $+\lambda_{2}$ CONTROL $+\pi_{1}$ 
(VIFs) for all variables. Low VIFs $(<2.0)$ and a VIF of less than 5 revealed that multicollinearity was 313 not present (O’Brien, 2007).

314 Factors other than institutional pressures can influence the climate change sensitivity of organisations and the level of adoption of mitigation and adaptation strategies, so we included control variables in the model. Large companies have more human and financial resources to adopt climate strategies and general environmental action (Daddi and Iraldo, 2016), thus two variables were included in the model related to size: the number of employees (EMPLOY) and annual turnover (TURNOV). The implementation of an environmental management system, and its certification according to standard ISO14001, was also considered as a control variable. ISO14001 is an international certification that requires companies to continually improve environmental performance, and it is widely implemented in several countries (Daddi et al., 2015). ISO14001 is a voluntary environmental tool for businesses (Testa et al., 2014), it is included in the model as it could influence the climate change sensitivity of the firms and the adoption of mitigation and adaptation strategies.

\subsubsection{Coercive, normative and mimetic pressures}

As described in the literature review, coercive, normative and mimetic pressures are key variables of institutional theory that cause isomorphic organisational choices among firms. To estimate institutional pressures, the measures relied on definitions given by DiMaggio and Powell (1983):

- coercive pressures: "coercive isomorphism refers to pressures from entities who have resources on which an organisation depends and by cultural expectations from society";

normative pressures: "normative isomorphism refers to following professional standards and practices established by education and training methods, professional networks and movement of employees among firms";

- mimetic pressures: "mimetic isomorphism refers to the imitation or copying of other successful organisations when an organisation is uncertain about what to do".

To estimate the variables COERCPRESS (coercive pressures), NORMPRESS (normative pressures), MIMETPRESS (mimetic pressures), one question of the questionnaire was designed to measure the perceived influence of diverse pressures on the organizational decision-making process with regard to environmental and climate change action. The question was: "How much have the following motivations influenced or could influence your decision to reduce the emissions of greenhouse gases or to further safeguard your business continuity from potential environmental risks and ecological emergencies"? Items were associated to the definitions of coercive, normative and mimetic pressures previously described and respondents answered by rating each item on a Likert scale from 1 to 5 where 1 was a strongly negative and 5 strongly positive. In particular:

- to estimate COERCPRESS, the following item was designed: "The law requires me, or it will impose on me soon, to adopt such initiatives";

- to estimate MIMETPRESS, the following item was designed: "My competitors are adopting or have already taken similar initiatives";

- to estimate NORMPRESS two items were combined through factor analysis, both linked to the concept of normative pressures, i.e.: "The implementation of these measures is functional to the adoption of the most recognized international environmental management standards" and "These initiatives ensure greater ability in the governance of the processes of prevention and management of environmental risks";

For NORMPRESS, the Alpha Cronbach coefficient was 0.708, which can be considered acceptable i.e. higher than 0.7 (Cortina, 1993).

\subsubsection{Climate change sensitivity, mitigation and adaptation strategies}


To measure climate change sensitivity and climate change strategies, specific items were developed and included in the questionnaire to estimate three variables: CLIMCHMSENS, MITIGSTRAT, ADAPTSTRAT.

Specifically, to estimate climate change sensitivity (CLIMCHMSENS), the questionnaire included the question: "How much is your organization aware of the possible consequences of global weather conditions on their production activities in the long run?" Respondents were asked to rate five different items on a scale 1-5 (1: strongly disagree; 5 strongly agree) (Table 2). Finally, a factor analysis was conducted to construct the variable.

\begin{tabular}{|c|c|c|}
\hline $\begin{array}{c}\text { Variable } \\
\text { abbreviation }\end{array}$ & $\begin{array}{c}\text { Question included in the } \\
\text { questionnaire }\end{array}$ & Items used in the estimation \\
\hline \multirow{5}{*}{ CLIMCHMSENS } & \multirow{5}{*}{$\begin{array}{l}\text { How much is your } \\
\text { organization aware of the } \\
\text { possible consequences of } \\
\text { global weather conditions } \\
\text { on their production } \\
\text { activities in the long run? }\end{array}$} & $\begin{array}{l}\text { The global weather conditions will have consequences } \\
\text { on the operations of production activities in the long } \\
\text { term }\end{array}$ \\
\hline & & $\begin{array}{l}\text { Emissions of greenhouse gases from production } \\
\text { activities have a real impact on global warming }\end{array}$ \\
\hline & & $\begin{array}{l}\text { Global warming will change the habits and lifestyles of } \\
\text { people }\end{array}$ \\
\hline & & $\begin{array}{l}\text { Ecological emergencies and extreme weather events } \\
\text { can have important consequences on production } \\
\text { activities and capital. }\end{array}$ \\
\hline & & $\begin{array}{l}\text { The future rise in the Earth's temperature and the } \\
\text { increase in the frequency and intensity of extreme } \\
\text { weather events could lead to serious implications for } \\
\text { the company's activities its the supply chain. }\end{array}$ \\
\hline
\end{tabular}

Table 2 Items used to build the variable climate change managerial sensitivity

Similarly, the adoption of mitigation and adaptation strategies was measured by 4 and 7 items of the questionnaire, respectively. Respondents were asked to rate the level of adoption of each mitigation and adaptation practice on a scale from 1 to 5 ,. Table 3 provides details of the item used to build the

\begin{tabular}{|c|c|c|}
\hline $\begin{array}{c}\text { Variable } \\
\text { abbreviation }\end{array}$ & $\begin{array}{c}\text { Question included in the } \\
\text { questionnaire }\end{array}$ & Items used in the estimation \\
\hline \multirow{4}{*}{ MITIGSTRAT } & \multirow{7}{*}{$\begin{array}{l}\text { What is the level of adoption } \\
\text { and development of the } \\
\text { following measures in } \\
\text { response to global warming } \\
\text { or potential extreme weather } \\
\text { events (eg floods, droughts, } \\
\text { heat waves, etc.) in your } \\
\text { organization? }\end{array}$} & $\begin{array}{l}\text { Measures aimed to improve the energy efficiency of } \\
\text { production activities }\end{array}$ \\
\hline & & Research and development activities \\
\hline & & $\begin{array}{l}\text { Modernization and modification of machinery and } \\
\text { plants in order to reduce greenhouse gas emissions }\end{array}$ \\
\hline & & $\begin{array}{l}\text { Involvement of partner companies, suppliers and } \\
\text { customers in collective measures to reduce emissions at } \\
\text { the supply chain level. }\end{array}$ \\
\hline \multirow{3}{*}{ ADAPTSTRAT } & & Business continuity plans \\
\hline & & Insurance coverage of capital, machinery and plants \\
\hline & & Research and development activities \\
\hline
\end{tabular}


Modernization and modification of machineries and plants in response to potential extreme weather events

Delocalization of plants and machineries

Changes in the procurement strategy

Involvement of partner companies, suppliers and customers in collective adaptation measures

Table 3 Items used to build the variables of mitigation strategies and adaptation strategies

The Alpha Cronbach measures of the three variables were $0.834,0.702,0.760$, confirming their reliability (Table 4).

\begin{tabular}{lllll}
\hline Variables & $\begin{array}{l}\text { Average inter-item } \\
\text { covariance }\end{array}$ & items & Alpha coefficient & Number of obs \\
\hline CLIMCHMSENS & 0.29578 & 5 & 0.834 & 624 \\
MITIGSTRAT & 1.02946 & 4 & 0.702 & 528 \\
ADAPTSTRAT & 0.81394 & 7 & 0.760 & 528 \\
\hline
\end{tabular}

Table 4 Alpha Cronbach coefficient of variables

\section{Results and discussion}

To ensure the feasibility and robustness of applying this statistical technique, equations were used for testing the hypotheses of the study and to confirm that the assumptions underlying the OLS regression were met. First, the normality of residuals was checked by plotting the non-parametric Kernel density estimator (Fan and Gencay, 1995), which revealed the symmetry of residual distribution. A Shapiro Wilk test was also conducted to check the normality of the distribution. Second, the homogeneity of variance of the residuals was checked using the Breusch-Pagan test, which indicated that heteroskedasticity did not affect the equations (the null hypothesis that the variance of the residuals is homogenous was not significant). The presence of collinearity in the equations was checked by computing the tolerance and variance inflationary factors for all variables. Low-variance inflation factors $(<2.0)$ and a variance inflationary factor of $<5$ revealed that multicollinearity was not present in the empirical model (O'Brien, 2007). Finally, to check for the presence of common method variance, the post hoc test Harman's one-factor test was conducted. This method enters all the variables into an exploratory factor analysis using unrotated principal component factor analysis. If a substantial common method variance is then present, either a single factor will emerge or one general factor will account for the majority of covariance among the variables (Steensmaet al., 2005). The results showed the presence of three distinct factors with eigenvalues greater than 1.0. The largest of these factors accounted for approximately $29 \%$ of the variance. Table 5 gives the descriptive statistics of the model.

\begin{tabular}{lllllllll}
$(1)$ & $(2)$ & $(3)$ & $(4)$ & $(5)$ & $(6)$ & $(7)$ & $(8)$ & $(9)$ \\
\hline
\end{tabular}

(1) COERCPRESS

(2) NORMPRESS

$0.46^{* *} \quad-$

(3) MIMETPRESS

$0.41^{* *} \quad 0.41^{* *} \quad-$

(4) CLIMCHMSENS

$0.29 * * \quad 0.36 * *$

$0.30^{* *}$

(5) MITIGSTRAT

$0.13 * * \quad 0.41 * *$

$0.16^{* *}$

(6) ADAPTSTRAT

0.02

$0.33 * *$

$0.11 *$

$0.19^{* *}$

$0.15 * * \quad 0.77 * *$ 


\begin{tabular}{lccccccccc} 
EMPLOY & 0.06 & 0.03 & 0.05 & -0.04 & $0.20^{* *}$ & 0.07 & - & & \\
TURNOV & 0.04 & 0.06 & 0.05 & -0.01 & $0.24 * *$ & $0.12^{*}$ & $0.73^{* *}$ & - & \\
ISO14001 & $0.11^{*}$ & $0.23^{* *}$ & $0.12^{*}$ & $0.11^{* *}$ & $0.23^{* *}$ & $0.12^{* *}$ & $0.13^{* *}$ & $0.20^{* *}$ & - \\
SD & 1.0232 & 0.7403 & 1.1188 & 0.9015 & 0.8106 & 0.8729 & 0.6657 & 0.6799 & 0.4997 \\
Min & 1 & -2.19 & 1 & -4.56 & -1.94 & -1.83 & 1 & 1 & 0 \\
Max & 5 & 1.05 & 5 & 1.47 & 1.43 & 2.42 & 4 & 4 & 2 \\
N & 512 & 512 & 512 & 624 & 528 & 528 & 426 & 412 & 625 \\
\hline
\end{tabular}

407 408 409

*Significant at 5\%. **Significant at 1\%. SD: Standard deviation.

Table 5. Correlation matrix and descriptive statistics

\subsection{The relation between institutional pressures and businesses climate change sensitivity}

The left side of our model refers to the first equation and test the influence of the three kinds of institutional pressures on climate change managerial sensitivity. Results indicate that companies' sensitivity towards climate change leads to the adoption of climate mitigation and adaptation strategies. It therefore acts as mediator between the pressures felt by the organisation and the actions they put in place to respond to these pressures.

The results of the model offer new and valuable insights into the corporate dynamics regarding institutional pressures. Specifically, the model shows that some institutional pressures are effective in increasing climate change sensitivity in companies, while other kinds of pressures are not significant. Table 6 reports the results from the left side of the model, i.e., the test of H1, H2 and H3.

\section{Climate change managerial sensitivity (CLIMCHMSENS)}

\begin{tabular}{lcc}
\hline & Coefficient & Standard deviation \\
\hline COERCPRESS & 0.0301 & 0.0415 \\
NORMPRESS & $0.2107 * * *$ & 0.0596 \\
MIMETPRESS & $0.1008^{* * *}$ & 0.0376 \\
EMPLOY & -0.1070 & 0.0793 \\
TURNOV & 0.0228 & 0.0776 \\
ISO14001 & $0.1294 *$ & 0.0760 \\
Number of observations & 409 & \\
R2 & 0.112 & \\
\hline
\end{tabular}

$*, * *$, and $* * *$ indicate the significance at $10 \%, 5 \%$, and $1 \%$, respectively

The first results confirm H1, highlighting the inefficacy of coercive regulatory pressures in increasing businesses' climate change sensitivity, and thus indirectly the adoption of mitigation and adaptation strategies. These insights also confirm the literature on ceremonial behaviour in other fields of environmental management (Boiral, 2007; Testa et al., 2017) and environmental policy in general. When a company feels "forced" to respond to an environmental commitment there is a compliance awareness but no pro-active behaviour, and in many cases it implies a lower effectiveness of the associated actions (Delmas and Toffel, 2008; Daddi et al., 2016). This negative reaction to coercive pressures has not always been previously identified, and in some cases when the regulation is 
"properly designed" it can increase environmental awareness and proactive action (Porter and Van der Linde, 1995; Horbach et al, 2013). Conversely, normative and mimetic pressures are positive and have high significance, demonstrating their capacity to increase the climate change sensibility of businesses and confirming $\mathrm{H} 2$ and $\mathrm{H} 3$. Normative pressures are linked with professional standards and rules. Typically, these are voluntary standards adopted by the organisations to improve their capacity to manage the environmental issues or to prevent risks. In the model, to assess the normative pressures we asked how relevant these professional standards were in reducing the emissions of greenhouse gases or in safeguarding business continuity. The results confirm that if an organisation felt significant normative pressures, they may start adopting voluntary initiatives, so these standards are likely to influence firms' awareness. Similarly, for coercive pressures these results extend and confirm previous observations in the field of climate change studies (Orsato et al. 2015), and institutional dynamics as observed in sustainable business studies (e.g. Delmas and Toffel, 2008; Daddi et al., 2016). Table 6 suggests that the mimetic isomorphism can also increase climate change sensitivity. The need to emulate first movers in the market creates higher climate change awareness in organisations and consequently a stronger adoption of mitigation and adaptation strategies. Companies often look to the "institutional" key players to identify their own strategies. This mimetic behaviour of taking inspiration from their competitors' experience is also confirmed by the results in the field of climate change. Finally, among the control variables, ISO14001 shows a positive and a slight significant relation with climate change sensitivity, as an international and voluntary environmental management standard. If a company is certified, it is probably subject to normative pressures (Berrone et al., 2013). This positive relation could thus be considered an indirect confirmation of the results of H2. ISO14001 also requires that companies continually improve their performance in all environmental aspects, climate change included. Therefore, we expect that ISO14001 can influence climate change managerial sensitivity and consequently the adoption of climate change strategies.

\subsection{The influence of climate change sensitivity in the adoption of mitigation and adaptation strategies}

The right side of the model aims at testing $\mathrm{H} 4$ and H5, and the results suggest that companies' climate change sensitivity influences both mitigation and adaptation strategies, therefore supporting both hypotheses (Tables 7 and 8).

\begin{tabular}{|c|c|c|}
\hline \multicolumn{3}{|c|}{ Mitigation strategies (MITIGSTRAT) } \\
\hline & Coefficient & Standard deviation \\
\hline CLIMCHSENS & $0.1888 * * *$ & 0.0467 \\
\hline EMPLOY & 0.758 & 0.0781 \\
\hline TURNOV & $0.182 * *$ & 0.0765 \\
\hline ISO14001 & $0.2358 * * *$ & 0.0729 \\
\hline Number of observations & 409 & \\
\hline $\mathbf{R 2}$ & 0.125 & \\
\hline \multicolumn{3}{|c|}{$*, * *$, and $* * *$ indicate the significance at $10 \%, 5 \%$, and $1 \%$, respectively } \\
\hline \multicolumn{3}{|c|}{ Adaptation strategies (ADAPTSTRAT) } \\
\hline & Coefficient & Standard deviation \\
\hline
\end{tabular}




\begin{tabular}{lcc}
\hline CLIMCHSENS & $0.2031 * * *$ & 0.0519 \\
EMPLOY & 0.0870 & 0.0870 \\
TURNOV & 0.1308 & 0.0852 \\
ISO14001 & 0.0876 & 0.0812 \\
Number of observations & 409 & \\
R2 & 0.055 & \\
\hline
\end{tabular}

$*, * *$, and $* * *$ indicate the significance at $10 \%, 5 \%$, and $1 \%$, respectively

Table 8 Results of the influence climate change sensitivity on adaptation strategies

These results suggest that companies with higher sensitivity towards climate issues are more driven to proactively implement voluntary mitigation and adaptation strategies (Kelly and Aedger, 2000). They confirm previous studies investigating the relation between climate change vulnerability and the effects of climate change on industries, both in terms of adaptation strategies (Gasbarro and Pinkse, 2015; Pinkse and Gasbarro, 2016) and mitigation strategies (Begum and Pereira, 2015).

The results also confirm that firms' sensitivity to climate change defines how they respond to climate change, therefore suggesting a proactive stance may be taken over environmental issues in response to institutional pressures (particularly normative and mimetic pressures). Previous studies focusing on adaptation strategies are also supported, which demonstrate that companies' adaptive behaviour may be aimed at reducing vulnerability to climate change, as it can originate from an assessment of exposure to climate risk (Yohe, 2000; Adger et al., 2003). However, mitigation strategies are also associated with resource efficiency objectives, which is not an obvious direct association. An ISO 14001-certified environmental management system is a significant control variable here, but only in relation to mitigation strategies and not adaptation strategies. This is not surprising as the rationale underlying the adoption of environmental management systems concerns pollution prevention, the reduction of environmental impacts from production processes and improvements in resource and energy efficiencies through research and development activities (Hoffman and Bush, 2008; Ansari et al., 2013; Daddi et al., 2016). These objectives overlap with several of the mitigation initiatives considered in this study. The control variable ISO 14001 thus indicates that in addition to climate change sensitivity, mitigation strategies are driven by the general level of environmental commitment, which are the basis for the adoption of certified environmental management systems. However, the adoption of adaptation strategies is not related to general environmental commitment associated with the ISO 14001 certification, but is exclusively driven by companies' sensitivity to climate change issues.

The economic benefits of mitigation and adaptation strategies should also be considered. Adaptation measures only aim to reduce the uncertainty associated with climate risk exposure, while mitigation strategies aim to secure competitive advantages (for example by imitating competitors' pioneering climate strategies) and operational or organizational improvements (i.e., enhancing environmental management capabilities) (Schotter and Goodsite, 2013). Furthermore, while benefits associated with mitigation measures are immediate, certain, measurable and predictable (e.g., energy savings), adaptation strategies require considerable upfront coordinating efforts to avoid the uncertain and unpredictable costs resulting from potential future business disruption.

The significance of company turnover as a control variable for mitigation strategies, rather than adaptation strategies, should also be noted. Turnover is a proxy of companies dimension and availability of resources, both financial and human. Thus, the more financial and human resources a company has, the greater its capacity and predisposition to implement environmental practices. These are typically aimed at improving business and organizational performance in terms of competitive positioning and energy or resource efficiency (Shrivastava, 1995). These considerations further 
confirm that climate change sensitivity can be the sole major driver of adaptation measures, and the role of ISO14001 in explaining the adoption of mitigation strategies, rather than adaptation strategies.

\section{Institutional pressures}

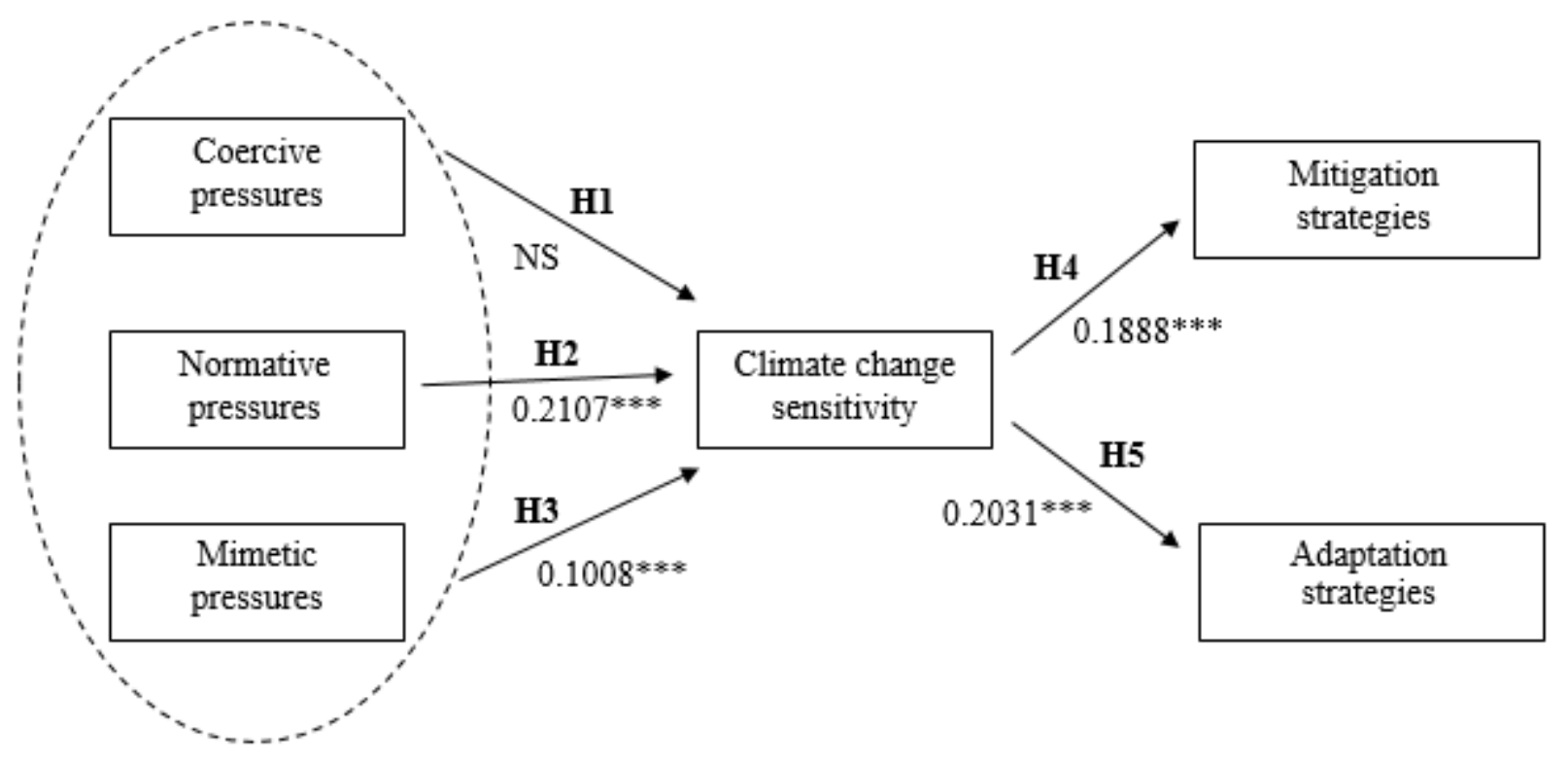

Figure 1. Results summary (NS: not significant)

\section{Conclusions}

The present study tests the applicability of institutional theory to the study of firms' behaviour with regard to climate change issues, and specifically in relation to the adoption of mitigation and adaptation strategies. The study contributes to climate change literature by (i) applying an institutional frame of analysis to business organizations, which several authors have noted is lacking (Goodall, 2008), and (ii) adding empirical insights on explanatory factors for business responses to climate change. From the perspective of institutional theory, the study confirms the usefulness of such approach and applications to the interface of politics, markets and business. As far as concerns the methodology adopted, survey questionnaires provide useful and in-depth insights on how firms perceive external pressures and how external pressures translate into the adoption of climate change practices (Daddi et al., 2018). In particular, results suggest that proactive climate change strategies (both mitigation and adaptation) originate from companies' sensitivity and readiness to act on climate issues in response to normative and mimetic, rather than coercive, pressures.

The results have both policy and managerial implications. In terms of policy implications, normative approaches should be encouraged, as they are more effective in incentivizing voluntary environmental practices. This implies that institutions such as trade associations, professional networks, clubs and other market constituencies should be engaged, to increase the legitimacy of the climate change discourse within the industry sector and, consequently, raise awareness of the private sector's role in mitigation and societal adaptation. Assessing the specific vulnerabilities of companies to climate risk, both in the form of direct and indirect effects (e.g., shifts in the demand for products or services), through appropriate climate risk assessment methodologies emerges as an initial step in increasing the uptake of both mitigation and adaptation strategies. Appropriate and well-designed policies can 
540 also be used as incentives, such as subsidies, artificial market mechanisms or regulatory reliefs, and 541 first-mover companies that address climate change issues by pioneering innovative mitigation or 542 adaptation strategies. Such policies should aim at triggering mimetic mechanisms in the market, thus 543 encouraging followers to adopt climate-friendly practices in their own respective sectors.

544 The study also identifies relevant avenues for future research. First, the various pressure factors and 545 how they relate to different corporate strategies can be identified. One limitation of this research is 546 that it focuses on a set of institutional pressures that are identified in the literature as the most 547 significant, but other factors can be considered as potential antecedents to corporate climate strategies. 548 In particular, market and policy factors that incentivize the adoption of more disruptive and innovative 549 climate change strategies can be addressed, as these can facilitate the fulfilment of the expectations 550 of the Paris Agreement by the industry sector. Second, future research can focus on the interface 551 between policy and business, by investigating what types of policy action are more conducive to 552 stimulating pro-active business behaviour, and how research can go beyond analysing the outcomes 553 of such regulation. Finally, further research should advance the understanding of policy and 554 normative instruments that can incentivize first-mover companies to involve actors along the supply555 chain (e.g., suppliers, distributors, final customers, etc.) in climate action, therefore extending 556 mitigation and adaptation beyond organizational and jurisdictional boundaries. 
Adger, W.N., Arnell, N.W., Tompkins, E.L., 2005. Successful adaptation to climate change across scales. Glob. Environ. Chang. 15(2), 77-86. Amran, A., Ooi, S.K., Wong, C.Y., Hashim, F., 2016. Business strategy for climate change: an ASEAN perspective. Corp. Soc. Resp. Env. Ma. 23(4), 213-227. Ansari, S., Wijen, F., Gray, B., 2013. Constructing a climate change logic: An institutional perspective on the "tragedy of the commons". Organ. Sci. 24(4), 1014-1040. decision to adapt to climate change: A case study in the Yom and Nan basins, Phichit province of Thailand. J. Clean. Prod. 143, 672-685.

Backman, C.A., Verbeke, A., Schulz, R.A., 2017. The drivers of corporate climate change strategies and public policy: a new resource-based view perspective. Bus. Soc. 56(4), 545-575.

Baron, R.M., Kenny, D.A., 1986. The moderator-mediator variable distinction in social psychological research: Conceptual, strategic, and statistical considerations. J. Pers. Soc. Psychol. 51(6), 1173.

Begum, R.A., Pereira, J.J., 2015. The awareness, perception and motivational analysis of climate change and business perspectives in Malaysia. Mitig. Adapt. Strat. Gl. 20(3), 361-370.

Berrone, P., Fosfuri, A., Gelabert, L., Gomez-Mejia, L.R., 2013. Necessity as the mother of 'green' inventions: institutional pressures and environmental innovations. Strategic Manage. J. 34, 891-909. Bleischwitz, R., 2003. Cognitive and Institutional Perspectives of Eco-Efficiency. Ecol. Econ. 46, 453-467.

Bleischwitz, R., 2004. Governance of sustainable development: co-evolution of corporate and political strategies, Int. J. Sustainable Development 7(1), 127-43.

Boiral, O., 2007. Corporate greening through ISO 14001: a rational myth? Organ. Sci. 18(1), 127146.

Cortina, J.M., 1993. What is coefficient alpha? An examination of theory and applications. J. Appl. Psychol. 78(1), 98.

Daddi, T., Iraldo, F., 2016. The effectiveness of cluster approach to improve environmental corporate performance in an industrial district of SMEs: a case study. Int. J. Sust. Dev. World 23(2), 163-173. Daddi, T., Frey, M., De Giacomo, M.R., Testa, F., Iraldo, F., 2015. Macro-economic and development indexes and ISO14001 certificates: a cross national analysis. J. Clean. Prod. 108, 12391248.

Daddi, T., Testa, F., Frey, M., Iraldo, F., 2016. Exploring the link between institutional pressures and environmental management systems effectiveness: an empirical study. J. Environ. Manage. 183, 647-656.

Daddi, T., Todaro, N.M., De Giacomo, M.R., Frey, M., 2018. A Systematic Review of the Use of Organization and Management Theories in Climate Change Studies. Bus. Strateg. Environ. 27(4), 456-474

Damert, M., Baumgartner, R.J., 2018. Intra-Sectoral Differences in Climate Change Strategies: Evidence from the Global Automotive Industry. Bus. Strateg. Environ. 27(3), 265-281.

Delmas, M.A., 2002. The diffusion of environmental management standards in Europe and the United States: an institutional perspective. Policy Sci. 35, 91-119.

Del Campo, A.G., 2017. A conceptualisation framework for building consensus on environmental sensitivity. Environ. Manage. 200, 114-122.

DiMaggio, P., Powell W.W., 1983. The iron cage revisited: institutional isomorphism and collective rationality in organizational fields. Am. Sociol. Rev. 48, 147-160

DiMaggio, P., 1988. Interest and Agency in Institutional Theory, in: Zucker, L. (Ed.), Institutional patterns and culture. Ballinger Publishing Co., Cambridge, pp.3-21.

Doh, J.P., Guay, T.R., 2006. Corporate social responsibility, public policy, and NGO activism in Europe and the United States: an institutional stakeholder perspective. J. Manag. Stud. 43(1), 47-73. 
Fan, Y., Gencay, R., 1995. A consistent nonparametric test of symmetry in linear regression models. 611 J. Am. Stat. Assoc. 90, 551-557.

612 Fleming, A., Rickards, L., Dowd, A.M., 2015. Understanding convergence and divergence in the 202-214.

Freudenburg, W.R., Muselli, V., 2010. Global warming estimates, media expectations, and the asymmetry of scientific challenge. Global Environ. Chang. 20(3), 483-491.

Galbreath, J., 2010. Corporate governance practices that address climate change: An exploratory study. Bus. Strateg. Environ. 19(5), 335-350.

Garud, R., Hardy, C., Maguire, S., 2007. Institutional entrepreneurship as embedded agency: an introduction to the special issue. Organ. Stud. 28, 957-969.

Gasbarro, F., Iraldo, F., Daddi, T., 2017. The drivers of multinational enterprises' climate change strategies: A quantitative study on climate-related risks and opportunities. J. Clean. Prod. 160, 8-26. Gasbarro, F., Pinkse, J., 2016. Corporate adaptation behaviour to deal with climate change: the influence of firm-specific interpretations of physical climate impacts. Corp. Soc. Resp. Env. Ma. 23(3), 179-192.

Goodall A.H., 2008. Why Have the Leading Journals in Management (and Other Social Sciences) Failed to Respond to Climate Change? J. Manag. Inq.17(4), 408-420.

Hahn, R., Reimsbach, D., Schiemann, F., 2015. Organizations, climate change, and transparency: Reviewing the literature on carbon disclosure. Organ. Environ. 28(1), 80-102.

Hoffmann, V.H., Busch, T., 2008. Corporate carbon performance indicators: Carbon intensity, dependency, exposure, and risk. J. Ind. Ecol. 12(4), 505-520.

Horbach, J., Oltra, V., Belin, J., 2013. Determinants and specificities of eco-innovations compared to other innovations - an econometric analysis for the French and German industry based on the community innovation survey. Industry and Innovation 20(6), 523-543.

Kelly, P.M., Adger, W.N., 2000. Theory and practice in assessing vulnerability to climate change andFacilitating adaptation. Clim. Change 47(4), 325-352.

Klein, R.J.T., Schipper, E.L.F., Desai, S., 2005. Integrating mitigation and adaptation into climate and development policy: Three research questions. Environ. Sci. \& Policy 8, 579-588

Kolk, A., Levy, D., Pinkse, J., 2008. Corporate responses in an emerging climate regime: the institutionalization and commensuration of carbon disclosure. Eur. Account. Review 17(4), 719-745 Kolk, A., Pinkse, J., Hull van Houten, L., 2010. Corporate responses to climate change: The role of partnerships, in: Martens, P., Chang, C.T. (Eds.), The social and behavioural aspects of climate change: Linking vulnerability, adaptation and mitigation. Sheffield, Greenleaf, UK, pp. 51-71.

Linnenluecke, M.K., Griffiths, A., Winn, M., 2012. Extreme weather events and the critical importance of anticipatory adaptation and organizational resilience in responding to impacts. Bus. Strateg. Environ. 21(1), 17-32

Lungarska, A., Chakir, R., 2018. Climate induced land use change in France: impacts of agricultural adaptation and climate change mitigation. Ecol. Econ. 147, 134-154.

Nozawa, W., Tamaki, T., Managi, S., 2018. On analytical models of optimal mixture of mitigation and adaptation investments. J. Clean. Prod. 186, 57-67.

O’brien, R.M., 2007. A caution regarding rules of thumb for variance inflation factors. Qual. Quant. 41(5), 673-690.

Orsato, R.J., de Campos, J.G.F., Barakat, S.R., Nicolletti, M., Monzoni, M., 2015. Why join a carbon club? A study of the banks participating in the Brazilian "Business for Climate Platform". J. Clean. Prod. 96, 387-396.

Pinkse, J., Gasbarro, F., 2016. Managing physical impacts of climate change: An attentional perspective on corporate adaptation. Bus. Soc. 58(2), 333-368.

Pinkse, J., Kolk, A., 2012. Addressing the climate change-sustainable development nexus: The role of multistakeholder partnerships. Bus. Soc. 51(1), 176-210. 
Podsakoff, P.M., MacKenzie, S.B., Lee, J.Y., Podsakoff, N.P., 2003. Common method biases in 661 behavioral research: A critical review of the literature and recommended remedies. J. Appl. Psychol. $66288,879$.

663 Porter, M.E., Van der Linde, C., 1995. Toward a new conception of the environment-competitiveness relationship. J. Econ. Perspect. 9(4), 97-118.

Sacchelli, S., Fabbrizzi, S., Bertocci, M., Marone, E., Menghini, S., Bernetti, I., 2017. A mix-method model for adaptation to climate change in the agricultural sector: A case study for Italian wine farms. J. Clean. Prod. 166, 891-900.

Schotter, A., Goodsite, M.E., 2013. Interdisciplinary perspectives on competitive climate strategy in multinational corporations. Thunderbird International Business Review 55(6), 629-632.

Scott, W.R., 1995. Organizations and institutions. Foundations for Organizational Science. Sage Publications, Thousand Oaks, CA, USA.

Shinkle, G.A., Spencer, J.W., 2012. The social construction of global corporate citizenship: Sustainability reports of automotive corporations. J. World Bus. 47(1), 123-133.

Shrestha, D., 2014. The Impacts of Climate Change on Business. Crossing the Border: International Journal of Interdisciplinary Studies 2(1), 93-112.

Shrivastava, P., 1995. Environmental technologies and competitive advantage. Strategic Manage. J. 16(S1), 183-200.

Steensma, H.K., Tihanyi, L., Lyles, M.A., Dhanaraj, C., 2005. The evolving value of foreign partnerships in transitioning economies. Acad. Manag. J. 48(2), 213-235.

Stoddart, M.C., Tindall, D.B., Greenfield, K.L., 2012. Governments have the power? Interpretations of climate change responsibility and solutions among Canadian environmentalists. Organ. Environ. 25(1), 39-58.

Stuart, D., Schewe, R.L., McDermott, M., 2012. Responding to climate change: Barriers to reflexive modernization in US agriculture. Organ. Environ. 25(3), 308-327.

Testa, F., Iraldo, F., Daddi, T., 2017. The Effectiveness of EMAS as a Management Tool: A Key Role for the Internalization of Environmental Practices. Organ. Environ. 31(1), 48-69.

Testa, F., Rizzi, F., Daddi, T., Gusmerotti, N. M., Frey, M., Iraldo, F., 2014. EMAS and ISO 14001: the differences in effectively improving environmental performance. J. Clean. Prod. 68, 165-173. UNFCCC, 2015. Adoption of the Paris agreement. United Nations Framework Convention on Climate Change Conference of the Parties. United Nations Framework Convention on Climate Change, Paris. https://unfccc.int/resource/docs/2015/cop21/eng/109r01.pdf (accessed 13 June 2019). Weinhofer, G., Busch, T., 2013. Corporate strategies for managing climate risks. Bus. Strateg. Environ. 22(2), 121-144.

Weinhofer, G., Hoffmann, V.H., 2010. Mitigating climate change-how do corporate strategies differ? Bus. Strateg. Environ. 19(2), 77-89.

Winn, M., Kirchgeorg, M., Griffiths, A., Linnenluecke, M.K., Günther, E., 2011. Impacts from climate change on organizations: A conceptual foundation. Bus. Strateg. Environ. 20, 157-173

Wittneben, B.B.F., Okereke, C., Banerjee, S.B., Levy, D.L. 2012. Climate Change and the Emergence of New Organizational Landscapes. Organ. Sci. 33(11), 1431-1450

Yohe, G., 2000. Assessing the role of adaptation in evaluating vulnerability to climate change. Clim. Change 46(3), 371-390. 